\title{
Application of Stochastic Simulation Method in Reliability Assessment of a PV-Wind-Diesel-SOFC Hybrid Microgrid
}

\author{
M. Moradi Ghahderijani, S. M. Barakati, and Ahmad Jamshidi
}

\begin{abstract}
In this paper, the sequential monte carlo simulation method is used to obtain the reliability indices of an isolated hybrid microgrid consist of diesel generator (DG), solid oxide fuel cell (SOFC), wind turbine generator (WTG), and photovoltaic system (PV). Some atmospheric data such as wind speed, solar irradiation, and ambient temperature data are used to achieve the output power of WTG and PV systems which can be obtained by two method; collecting data from weather station or using the computer programs. For this purpose, Weibull distribution is used. To obtain the adequacy model of DG and SOFC, a two state reliability model is used. A combination of this model and output power formulation is also used to achieve the generation model of WTG, and PV systems. Furthermore, the total generation model is compared with IEEE reliability test system (IEEE RTS) load model and the reliability indices are then achieved, which show the effectiveness of the SMCS method in reliability evaluation of both stable and unstable resources like WTG and PV.
\end{abstract}

Index Terms-Microgrid, photovoltaic, wind turbine generator, monte carlo simulation.

\section{INTRODUCTION}

The actual generation of power system structures must adapt to environmental policies, customer concerns, and reliability issues. The clean energy like wind and solar power should be considered for future power systems. Moreover, the recent challenges related to blackouts and power quality issues such as load changes are required a new concept of Micro Grid for future electric power supply [1]. The study in reliability of renewable energy systems have been reported in the beginning of 1980s. The reliability modeling and analysis of stand-alone PEM fuel cell power plants is carried out in [2] Reference [3] developed and formulated a standard reliability terminology of photovoltaic power systems. In [4], the reliability of a photovoltaic system is evaluated which a reliability block diagram is developed to model system behavior and estimate the reliability of the system. The reliability parameters of a PV system are also estimated in [5] In [6], some ways to achieve a higher reliability of a stand-alone hybrid power system is discussed. Billinton et al. evaluated the reliability and cost implications of a small isolated power system [7]. In their paper, some composite system indices are evaluated using Monte Carlo Simulation technique. Recently, to assess the reliability indices of a microgrid system, including WTG and micro gas turbine (MGT), a model was developed and applied to SMCS[8].

Manuscript received June 20, 2012; revised August 21, 2012.

The authors are with the Electrical Engineering Department, University of Sistan and Baluchestan, Zahedan, Iran (e-mail: mmghahderijani@yahoo.com).
In this paper, a microgrid including some renewable energy supplies such as PV, WTG, SOFC, and DG with different configurations are studied to evaluate the system reliability indices. To model DG and SOFC, a two-state model is employed. To model the availability of PV and WTG, a combination of the two-state model and their inherent characteristics should be used. To evaluate the microgrid reliability indices, the IEEE RTS load model [9] is compared with the developed generation model. There are two reliability evaluation approaches: deterministic and probabilistic [10]. The deterministic approaches cannot identify the random behavior of the microgrid systems. To calculate the reliability indices of both stable and unstable resources like WTG and PV, the generation and load models are applied to the sequential MCS, as a probabilistic approach.

The work in this study is organized as follows: in Section 2, the electrical output power of wind system is modelled. The delivered output power of the PV system is formulated in Section 3. The adequacy assessment methodology of the microgrid system is introduced in Section 4 consist of microgrid generation and the load demand models. Section 5 is dedicated to present some case studies. Conclusion and future considerations are summarized in the last section of the paper.

\section{MICROGRID COMPONENTS}

\section{A. Solid Oxide Fuel Cell}

Solid Oxide Fuel Cells (SOFC) are particularly attractive because they are the most efficient in terms of fuel input to electricity output. The technology is best applicable in the MG. The high operating temperature produces heat suited well to cogeneration applications.

For calculating the stack voltage, Nernst's equation and Ohm's law (to consider ohmic losses) are applied. The stack output voltage $V^{r}$ can be represented by the following expression:

$$
V^{r}=N_{0}\left(E_{0}+\frac{R_{\text {gass }} T}{2 F}\left[\ln \frac{P_{H 2} P_{O 2}^{0.5}}{P_{H 2 O}}\right]\right)-r_{\text {loss }} I^{r},
$$

where $E_{0}$ is the voltage associated with the reaction free energy [V]. $R_{\text {gass }}$ is the gas constant, but care should be taken with the system unit [Jkmol:K]. $r_{\text {loss }}$ describes the ohmic losses of the stack. N0 is the number of cells associated in series in the stack, $\mathrm{T}$ and $\mathrm{F}$ are the cell temperature and Faraday's constant, respectively. $I^{r}$ is the stack current. $P_{H 2 O}$, $P_{H 2}$, and $P_{O 2}$ are the partial pressure of $\mathrm{H}_{2} \mathrm{O}, \mathrm{H}_{2}$, and $\mathrm{O}_{2}$, respectively. 


\section{B. Wind System Model}

The static model of the wind energy system is used in reliability assessment consideration. The output power of a wind energy system depends on the wind velocity and its power curve. To depict the wind characteristics, a wind speed probability distribution based on Weibull distribution is used. where $\alpha$ is the scale parameter, $\beta$ the shape parameter of Weibull distribution, and $\mathrm{v}$ the wind speed. To simulate the wind speed data the following equations can be used using the uniformly distribution random number $U$ between $[0,1]$ :

$$
\begin{gathered}
v=\alpha(-\ln U)^{1 / \beta}, \\
\alpha=\bar{v} / \Gamma(1+1 / \beta), \\
\beta=(\sigma / \bar{v})^{-1.086,}
\end{gathered}
$$

where $\bar{v}$ refers to the average value of wind velocity and $\sigma$ stands for standard deviation of wind speed and $\Gamma$ represent the gamma function.

To model the wind system performance, its power curve must be also formulated in the form of polynomials as below [8]:

$$
\begin{aligned}
& p_{W T G}=\left\{\begin{array}{lc}
0 & 0<v<v_{\text {cut-in }} \\
a v^{k}+b P_{\text {rated }} & v_{\text {cut-in }}<v<v_{\text {rated }} \\
P_{\text {rated }} & v_{\text {rated }}<v<v_{\text {cut-out }} \\
0 & 0<v<v_{\text {cut-in }}
\end{array},\right. \\
& a=\frac{P_{\text {rated }}}{v_{\text {rated }}^{3}-v_{\text {cut }- \text { out }}^{3}}, \\
& b=\frac{v_{\text {cut-in }}^{3}}{v_{\text {rated }}^{3}-v_{\text {cut }- \text { out }}^{3}},
\end{aligned}
$$

where Prated,$v_{\text {cut-in }}$, and $v_{\text {cut-out }}$ are the rated power, cut-in, and cut-out wind velocity, respectively. Moreover, $v_{\text {rated }}$ and $v$ are the rated and actual wind speed, obtained from the mentioned algorithm, respectively. A power curve of a wind system is shown in Fig. 1. The WTG characteristics are listed in Table I [11].

\begin{tabular}{cccc}
\multicolumn{4}{c}{ TABLE I: WTG CHARACTERISTIC. } \\
\hline \hline $\mathbf{P}_{\text {rated }}[\mathbf{k w}]$ & $\mathbf{V}_{\text {cut-in }}[\mathbf{m} / \mathbf{s}]$ & $\mathbf{V}_{\text {rated }}[\mathbf{m} / \mathbf{s}]$ & $\mathbf{V}_{\text {cut-out }}[\mathbf{m} / \mathbf{s}]$ \\
\hline 20 & 3 & 12 & 25 \\
\hline
\end{tabular}

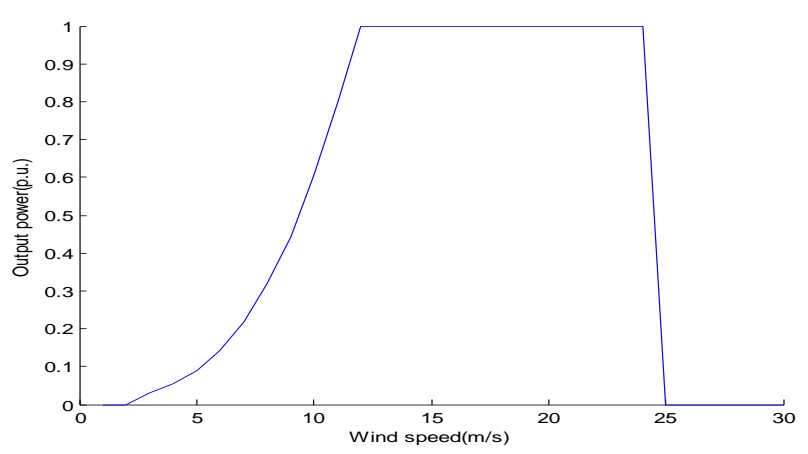

Fig. 1. The power curve of a typical WTG.

\section{Photovoltaic System Model}

The algorithm was used to obtain wind velocity data, can be also used to achieve the solar irradiation and ambient temperature data. The maximum power produced by a PV module under standard test conditions (STC) can be used to evaluate the module rated power in peak-watt. This test should be performed in a radiation level of $1 \mathrm{~kW} / \mathrm{m} 2$ and a cell temperature of $25^{\circ} \mathrm{c}$. The electrical powers generated by a PV array consist of $\mathrm{N}$ modules can be computed using equations below [6]:

$$
\begin{gathered}
T_{C}=T_{A}+\frac{s\left(N_{O T}-20\right)}{0.8}, \\
I=s\left[I_{S C}+K_{I}\left(T_{C}-25\right)\right], \\
V=V_{O C}-K_{V} T_{C}, \\
F F=\frac{V_{M P P} I_{M P P}}{V_{O C} I_{S C}} \\
P_{P V}=N * F F * V * I .
\end{gathered}
$$

where $s$ and $T_{A}$ are the radiation level and the ambient temperature, respectively. $T_{C}$ is the cell temperature $\left(\mathrm{c}^{\circ}\right), \mathrm{I}$ refers to short-circuit current of a $\mathrm{PV}$ module in $\mathrm{A}, K_{I}$ indicates the temperature factor of the short-circuit current in terms of $\mathrm{A} /{ }^{\circ} \mathrm{C}, V$ represents the open-circuit voltage, and $\mathrm{KV}$ is open-circuit voltage temperature factor $\left(\mathrm{V} /{ }^{\circ} \mathrm{C}\right)$. Also to evaluate the output power of a PV, calculation of fill factor $(F F)$ is needed. $V_{M P P}$ and $I_{M P P}$ represent voltage and current in maximum power point, respectively, while $V_{O C}$ is the open-circuit voltage and $I_{S C}$ refers to short-circuit current, which these values are given in PV catalogue by the manufacturer.

A PV array with 5 modules per string and 10 strings in parallel is utilized in this work. The PV modules are produced by Mitsubishi Electric with the parameters given in Table II [12].

TABLE II: PV CHARACTERISTIC

\begin{tabular}{cccccc}
\hline \hline $\mathrm{I}_{\mathrm{SC}}[\mathrm{A}]$ & $\mathrm{V}_{\mathrm{OC}}[\mathrm{V}]$ & $\mathrm{V}_{\mathrm{MPP}}[\mathrm{V}]$ & $\mathrm{I}_{\mathrm{MPP}}[\mathrm{A}]$ & $\mathrm{K}_{\mathrm{I}}$ & $\mathrm{K}_{\mathrm{V}}$ \\
7.36 & 30.4 & 24.2 & 6.83 & $0.057 \%$ & $-0.346 \%$ \\
\hline
\end{tabular}

\section{AdeQuacy Assesment Method}

The MCS method is a general designation for stochastic simulation using random numbers. In this method the random behaviors of the system are simulated [9]. In this study, the state duration sampling approach, which is a kind of the sequential MCS method, is applied to Microgrid system.

Consequently, a series of information in a time sequence are produced and the adequacy indices from a series of simulated experiments can be calculated. An adequacy assessment model for stand-alone Microgrid system is shown in the following subsection.

\section{A. DG and SOFC Generation Model}

The reliability model of DG and SOFC is obtained using the state duration sampling approach. In this study, a two-state reliability model is used. The time to failure (TTF) 
and time to repair (TTR) of DG and SOFC can be achieve by the following algorithm:

1) step1: generating two uniformly distributed random numbers $U$ and $U^{\prime}$ between $[0,1]$.

2) step2: computing TTR and TTF by equations below [9]:

$$
\begin{aligned}
& T T F=-M T T F \cdot \ln U, \\
& T T R=-M T T R \cdot \ln U^{\prime},
\end{aligned}
$$

where MTTF and MTTR are the mean time to failure and repair, respectively.

\section{B. WTG Generation Model}

To obtain the adequacy model of a WTG, a combination of two-state model used in SOFC and DG reliability model and the output power given in equation (3), can be used as shown in Fig. 2.

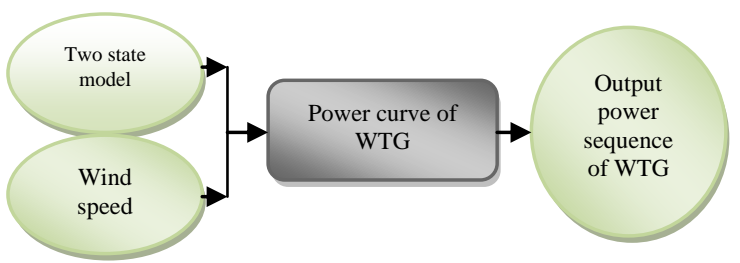

Fig. 2. Generation model of WTG.

\section{PV Generation Model}

Two-state unit model used in previous section can also be adopted in a PV system. The output power of PV should also be consider to achieve the PV reliability model as illustrated in Fig. 3.

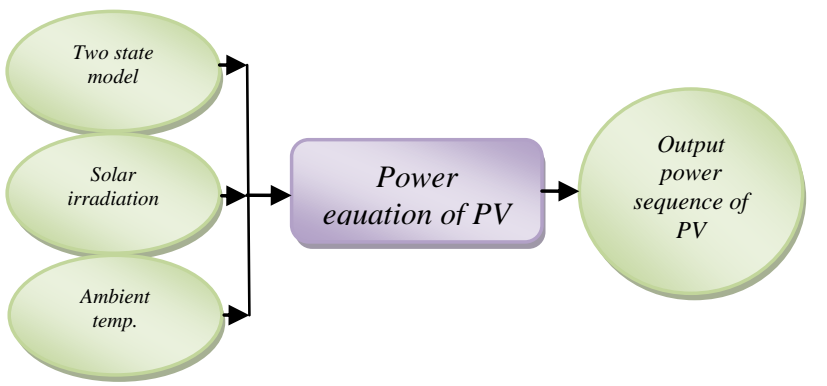

Fig. 3. Generation model of PV.

\section{Load Model}

In this paper, the IEEE reliability test system (RTS) load model is used to compare with system availability and evaluate the reliability indices [9]. This model is shown in Fig. 4.

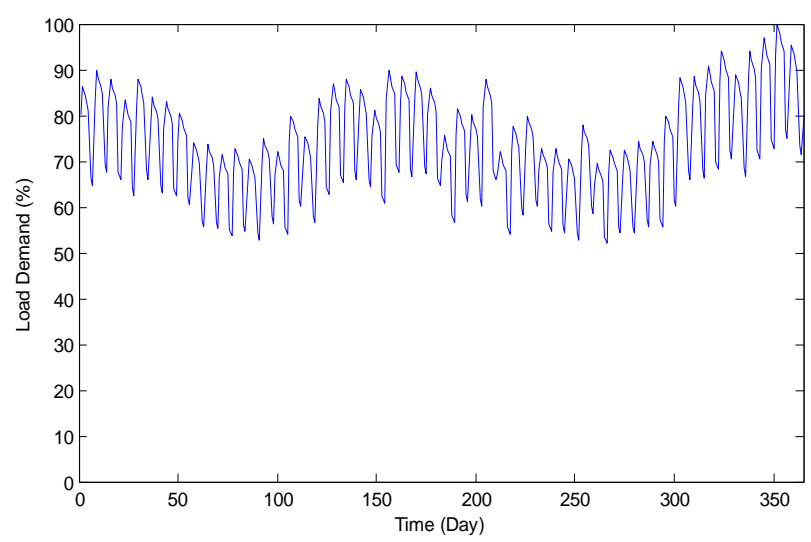

Fig. 4. IEEE RTS load model in percentage of peak load.

\section{CAse Study}

In this study, different structures of microgrid including DG, WTG, PV, and SOFC as listed in Table III is used to show the effectiveness of each energy supply in total reliability of the system. The mean values of wind speed, ambient temperature, and solar radiation are given in this Table. IEEE RTS load with peak value equal to $560 \mathrm{kw}$ also considered. All the mentioned cases are applied to the sequential MCS to obtain the reliability indices. The reliability computation results are given in Table IV. Case 1 is the basic microgrid system consist of ten $32 \mathrm{~kW}$ DG and five $60 \mathrm{~kW}$ SOFC without any PV and wind turbine generator. The results show that the loss of load expectation (LOLE) is 0.176 day/yr and the loss of load frequency (LOLF) is $0.141 \mathrm{occ} / \mathrm{yr}$ which represents the high reliability level of SOFC and DG.

TABLE III: MICROGRID STRUCTURE

\begin{tabular}{cccccccc}
\hline \hline Structures & $\begin{array}{c}\text { DG } \\
\mathbf{3 2 k w}\end{array}$ & $\begin{array}{c}\text { SOFC } \\
\mathbf{6 0 k w}\end{array}$ & $\begin{array}{c}\text { PV } \\
\mathbf{4 0 k w}\end{array}$ & $\begin{array}{c}\text { WTG } \\
\mathbf{2 0 k w}\end{array}$ & $\begin{array}{c}\text { Wind } \\
\text { spead[m/s] }\end{array}$ & $\begin{array}{c}\text { Ambient } \\
\text { temp. }\left[{ }^{\circ} \mathbf{C}\right]\end{array}$ & $\begin{array}{c}\text { Solar } \\
\text { radiation } \\
{\left[\mathbf{k w} / \mathbf{m}^{2}\right]}\end{array}$ \\
\hline Case1 & 10 & 5 & 0 & 0 & - & - & - \\
Case2 & 10 & 5 & 0 & 2 & 4.0625 & - & - \\
Case3 & 9 & 5 & 0 & 2 & 4.0625 & - & - \\
Case4 & 10 & 5 & 1 & 0 & - & 25 & 1.366 \\
Case5 & 9 & 5 & 1 & 0 & - & 25 & 1.366 \\
Case6 & 8 & 5 & 1 & 2 & 4.0625 & 25 & 1.366 \\
\hline
\end{tabular}

TABLE IV: RELIABILITY RESULTS

\begin{tabular}{ccc}
\hline \hline Structure & LOLE[Day/yr] & LOLF[Occ/yr] \\
\hline Case1 & 0.172 & 0.138 \\
Case2 & 0.068 & 0.053 \\
Case3 & 0.519 & 0.372 \\
Case4 & 0.093 & 0.071 \\
Case5 & 0.611 & 0.445 \\
Case6 & 1.468 & 0.986 \\
\hline
\end{tabular}

In case2, two $20 \mathrm{~kW}$ WTGs are also added to the basic system. WTG and PV deduce the consumption rates of natural gas and fuel of DG.

Case 3 has a similar structure to case 1 but two $20 \mathrm{kw}$ WTGs replace with a $32 \mathrm{~kW}$ DG. The simulation results show that in this case the reliability indices are became worse because of the dependence of wind on nature and environment. In such a situation a battery storage can be used. The results of this case are shown in Fig. 5 and Fig. 6.

The days of trouble probability histogram of case 3 is shown in Fig. 7. In case 4, a $40 \mathrm{~kW}$ PV array is added to basic system in case1, so our system became more reliable than case1. Case 5 is similar to case 1 , but a $32 \mathrm{~kW}$ DG unit is removed and a PV array is added to case1. The MCS results prove that the reliability of our system is became worse like case3. It's also because of the nature of PV systems which depends on the weather conditions and cannot guarantee a good availability. In this case also a battery storage can be fruitful. In the last case, which has similar configuration to case 5 only two $32 \mathrm{~kW}$ WTG are added and one of the DG 
units is removed, in another word, comparing with case 1 a $40 \mathrm{~kW}$ PV array and two $20 \mathrm{~kW}$ WTGs are replaced with two 32 DG units. The microgrid system, in this case is more unreliable than case 1 due to the nature of PV and WTG systems.

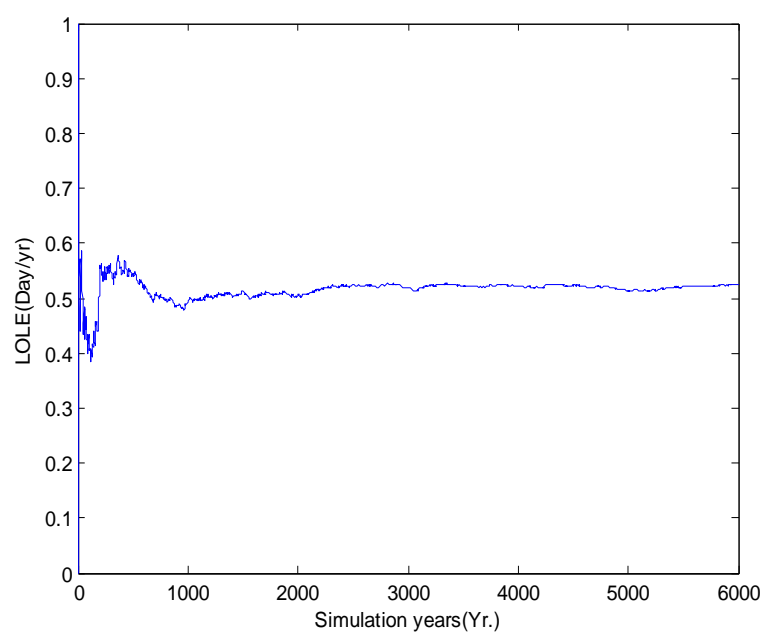

Fig. 5. LOLF results of case3.

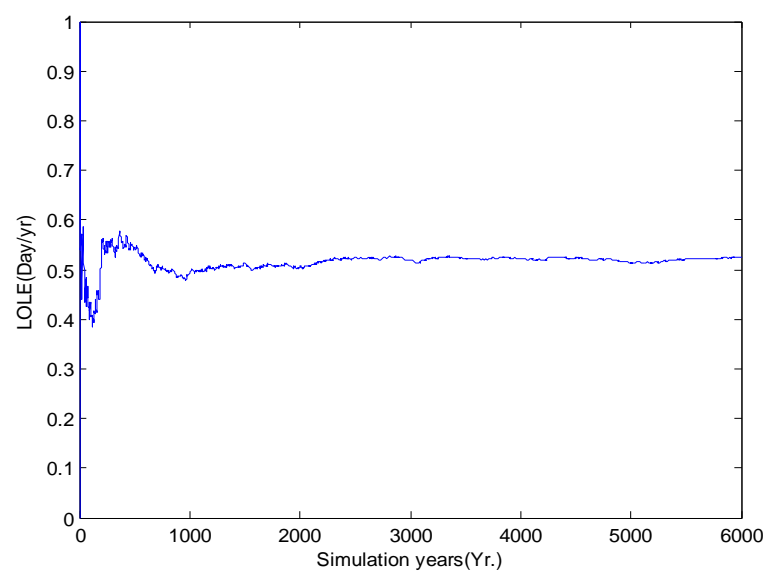

Fig. 6. LOLE results of case3.

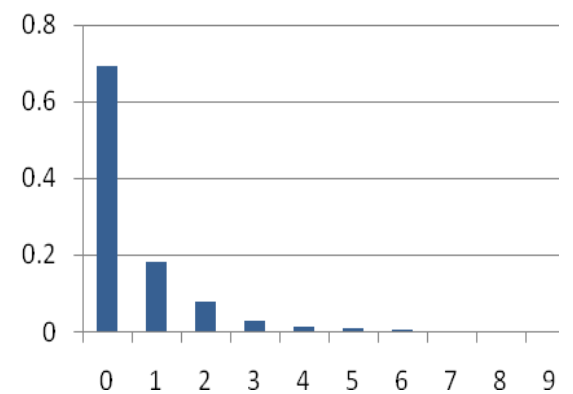

Fig. 7. Trouble days probability histogram of case 3 .

\section{CONCLUSION}

Reliability assessment of a hybrid microgrid consist of DG, SOFC, WTG, and PV system, is carried out using SMCS. The generation model of each supply is separately built. Then, the total generation model of microgrid is constructed and compare with IEEE-RTS load model to calculate the reliability indices using SMCS. The simulation results prove that WTG and PV systems are more unreliable than the other kind of local distributed resources, because of their nature which depend on weather condition. However, using a storage system can increase the stand-alone microgrid system reliability. Also the economical aspects can be taken into account in adequacy study of microgrid.

\section{REFERENCES}

[1] Y. L. Su and N. Ken, "Monte Carlo simulation method used in reliability evaluation of a laboratory-based micro grid," Proceeding of IMECS, Hong Kong, 2010.

[2] M. Tanrioven and M. S. Alam, "Reliability modeling and analysis of stand-alone PEM fuel cell power plants," IEEE Trans. on Renewable Energy, vol. 1, no. 7, 2005.

[3] A. Harold, Lauffenburger, and R. T. Anderson, "Reliability Terminology and Formulae for Photovoltaic Power Systems," IEEE Trans. on Reliability, vol. r-31, no. 3, pp. 289-295, 1982.

[4] E. Collins, M. Dvorack, J. Mahn, M. Mundt, and M. Quintana, "Reliability and availability analysis of a fielded photovoltaic system," International Applied Reliability Symposium, 2009.

[5] A. Pregelj, M. Begovic, A. Rohatgi, and A. Ristow, "Estimation of PV System Reliability Parameters," in Proc. 2001 Photovolt. Sol. Energy Conf. Exhib., Munich, Germany., pp. 558-561.

[6] W. Zhou, C. Lou, Z. Li, L. Lu, and H. Yang, "Current status of research on optimum sizing of stand-alone hybrid solar-wind power generation systems," in Proc. 2010 Applied Energy 87, pp. 380-389.

[7] R. Billinton and A. Jonnavithula, "Application of sequential Monte Carlo simulation to evaluation of distributions of composite system indices," in Proc. 1997 IEE Generation, Transmission and Distribution conf., pp. 87-90.

[8] L. B. Fang and J. D Cai, "Reliability assessment of microgrid using sequential monte carlo simulation," in Proc. 2011 Journol of Electronic Science and Technology., pp. 31-34.

[9] R. Billinton and W. Li, Reliability Assessment of Electric Power Systems Using Monte Carlo Methods, New York: Plenum, 1994, pp. 300.

[10] R. Billinton and R. Alen, "Reliability evaluation of power systems," 2nd ed. New York: Plenum, 1994, pp. 400-442.

[11] L. N. Kishore and E. Fernandez, "Reliability well-being assessment of PV-wind hybrid system using Monte Carlo simulation," in Proc. ICETECT, pp. 63-68, 2011.

[12] A. Chatterjee, A. Keyhani, and D. Kapoor, "Identification of photovoltaic source models," IEEE PES Trans. on Energy Conversion, 2011.

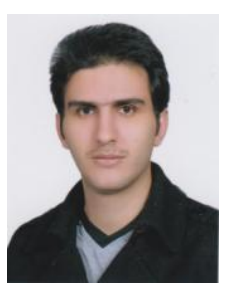

Mohammad Moradi Ghahderijani received the B.Sc. degree in electrical engineering from University of Najafabad, Isfahan, Iran in 2009 . He is currently a Master student in the Department of Electrical and Computer Engineering, University of Sistan and Baluchestan, Zahedan, Iran. His fields of interests include Microgrid, optimization, reliability and power electronic studies.

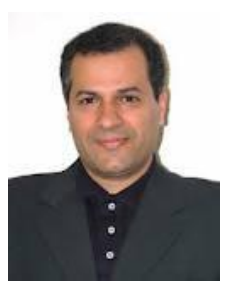

Seyyed Masoud Barakati received the B.Sc. degree from Ferdowsi University of Mashhad, Mashhad, Iran, in 1993, the M.Sc. degree from Tabriz University, Tabriz, Iran, in 1996, the Ph.D. degree from the University of Waterloo, Waterloo, Canada, in 2008, and the post-doctoral position in University of Wisconsin-Madison, Madison, Wisconsin, USA, all in electrical engineering. $\mathrm{He}$ is currently an assistant-professor in University of Sistan and Baluchestan. His current research interests include power electronic circuits, control systems, and renewable energy.

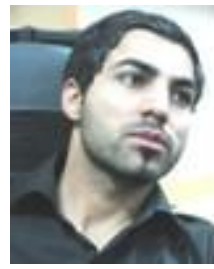

Ahmad Jamshidi received the B.Sc. degree in electrical and electronic engineering from Shiraz University, Shiraz, Iran, in 2010. He is currently pursuing the M.Sc. degree in the area of FACTS and custom power devices at the University of Sistan and Baluchestan, Zahedan, Iran. His research interests are in FACTS and custom power devices and power electronics. 